\title{
Long-term monitoring and experimental manipulation of a Chihuahuan desert ecosystem near Portal, Arizona (1977-2013)
}

\author{
S. K. Morgan Ernest, ${ }^{1,2,11}$ Glenda M. Yenni, ${ }^{1,2}$ Ginger Allington,,${ }^{3}$ Erica M. Christensen, $, 1,2$ \\ Keith Geluso, ${ }^{4}$ Jacob R. Goheen, ${ }^{5}$ Michelle R. Schutzenhofer,${ }^{6}$ Sarah R. Supp, \\ Katherine M. Thibault,${ }^{8}$ James H. Brown, ${ }^{9}$ and Thomas J. Valone ${ }^{10}$ \\ ${ }^{1}$ Department of Biology, UMC 5305, Utah State University, Logan, Utah 84322, USA \\ ${ }^{2}$ Department of Wildlife Ecology and Conservation, University of Florida, 110 Newins Ziegler Hall, PO Box 110430, Gainesville, \\ Florida 32611, USA \\ ${ }^{3}$ School of Natural Resources and Environment, University of Michigan, 440 Church St., Ann Arbor, Michigan 48109, USA \\ ${ }^{4}$ Department of Biology, The University of Nebraska at Kearney, 905 West 25th Street, Kearney, Nebraska 68849, USA \\ ${ }^{5}$ Departments of Zoology \& Physiology and Botany, University of Wyoming, 1000 E. University Ave, Laramie, Wyoming 82071 , \\ USA \\ ${ }^{6}$ McKendree University, 701 College Road, Lebanon, Illinois 62254, USA \\ ${ }^{7}$ School of Biology \& Ecology, University of Maine, Deering Hall 303, Orono, Maine 04469, USA \\ ${ }^{8}$ NEON, 1685 38th Street Suite 100, Boulder, Colorado 80301, USA \\ ${ }^{9}$ Department of Biology, University of New Mexico, 167 Castetter Hall, MSC03 2020, Albuquerque, New Mexico 87131, USA \\ ${ }^{10}$ Department of Biology, St. Louis University, 3507 Laclede Ave., St. Louis, Missouri 63103, USA
}

Abstract. Desert ecosystems have long served as model systems in the study of ecological concepts (e.g., competition, resource pulses, top-down/bottom-up dynamics). However, the inherent variability of resource availability in deserts, and hence consumer dynamics, can also make them challenging ecosystems to understand. Study of a Chihuahuan desert ecosystem near Portal, Arizona began in 1977. At this site, 24 experimental plots were established and divided among controls and experimental manipulations. Experimental manipulations over the years include removal of all or some rodent species, all or some ants, seed additions, and various alterations of the annual plant community. This dataset includes data previously available through an older data publication and adds 11 years of data. It also includes additional ant and weather data not previously available. These data have been used in a variety of publications documenting the effects of the experimental manipulations as well as the response of populations and communities to long-term changes in climate and habitat. Sampling is ongoing and additional data will be published in the future.

Key words: annual plants; ants; Chihuahuan desert; long-term data; precipitation; rodents; temperature.

The complete data sets corresponding to abstracts published in the Data Papers section in the journal are published electronically as Supporting Information in the online version of this article at http://onlinelibrary.wiley.com/doi/10.1890/ 15-2115.1/suppinfo

Manuscript received 1 December 2015; accepted 15 December 2015. Corresponding Editor: W. K. Michener.

${ }^{11}$ E-mail: skmorgane@ufl.edu 